\title{
Journal of HIV and AIDS
}

\section{CerebellarTuberculomain aHIV Coinfected Patient with Arnold-Chiari I Malformation}

Benabdellah A ${ }^{1}$, Bachir N², Belharane $A^{2}$, Benabadji A $^{2}$, Benchouk $\mathrm{S}^{2}$, Bensaha $\mathrm{Z}^{2}$, Bensaad $\mathbf{M}^{2}$, Brahimi $\mathrm{H}^{2}$, Lakhdori $\mathrm{F}^{2}$, Mahamdaoui $\mathrm{F}^{2}$, Mahmoudi $\mathbf{R}^{2}$, Taleb-Bendiab $\mathbf{R}^{2}$, Allal-Taouli $\mathrm{K}^{2}$, Labdouni $\mathrm{MH}^{2}$, Bensenane $\mathrm{M}^{3}$ and Berrada $\mathrm{S}^{3}$

${ }^{\prime} H I V$ laboratory research, University of Oran, Algeria

${ }^{2}$ CHU TLEMCEN, University of Oran, Algeria

${ }^{3}$ CHU ORAN, University of Oran, Algeria

"Corresponding author: Benabdellah Anwar, HIV laboratory research, University of Oran, BP 1524 ELM_Naouer 31000 Oran, Algeria, Tel: +213 (0) 41581947 /+213 (0) 4158 19 41; E-mail: benabdellah.anouar@univ-oran.dz
Received date: 18 May 2015; Accepted date: 04 June 2015; Published date: 10 June 2015

Citation: Benabdellah A, Bachir N, Belharane A, Benabadji A, Benchouk S, et al. (2015) Cerebellar Tuberculoma in a HIV Coinfected Patient with Arnold-Chiari I Malformation. J HIV AIDS 1 (1): doi http://dx.doi.org/10.16966/2380-5536.104

Copyright: (C) 2015 Benabdellah A, et al. This is an open-access article distributed under the terms of the Creative Commons Attribution License, which permits unrestricted use, distribution, and reproduction in any medium, provided the original author and source are credited.

\begin{abstract}
The four types of Chiari malformations, as described by Dr. Hans Chiari, have neither anatomic nor embryologic correlation. Their only commonality is that they all involve the cerebellum. Chiari I malformation consists of herniation of the cerebellar tonsils into the foramen magnum, thus crowding the craniocervical junction. Chiari II malformation is almost exclusively associated with myelomeningocele and hydrocephalus. It consists of herniation of not only the tonsils but also all the contents of the posterior fossa into the foramen magnum. This herniation involves the brainstem, fourth ventricle, and cerebellar vermis. Chiari III and IV malformations are rare. Chiari III represents an encephalocele (external sac containing brainstem and posterior fossa contents); thus, the cerebellum and brainstem are descending not only into the spine, but also into an external sac. Chiari IV consists of cerebellar hypoplasia. The Chiari I malformation has the latest mean age of clinical presentation. A Chiari type I anomaly presenting in adulthood is the focus of this case report. Surgery is indicated with neurological dysfunction, symptomatic syrinx, or hydrocephalus. Of all Chiari I patients, $15 \%-20 \%$ will have hydrocephalus. For some of them, the hydrocephalus will resolve with ventriculoperitoneal shunting, alleviating the need for a Chiari decompression. Long-term prognosis for patients with symptomatic Chiari type I malformations who undergo surgical treatment is variable, based on the patients presenting symptoms and spinal cord cyst response.
\end{abstract}

Keywords: Cerebellar tuberculoma; Arnold-Chiari malformation; HIV infection

\section{Introduction}

Tuberculosis has become more frequent since the emergence of HIV infection epidemics. Nowadays, there are important challenges, which complicate the management of HIV-TB co-infected patients. Among them, it is emphasized the increase of disseminated and extra-pulmonary tuberculosis forms, the multi-drug resistance and the increase in mortality.

The central nervous system tuberculosisis found in $5-10 \%$ of patients with pulmonary tuberculosis. These cases correspond to either latent infection reactivations or disseminated infections. Tuberculous meningitis is the most common clinical form and it is five times more frequent in patients with HIV infection than in patients without it. The focal forms of central nervous system tuberculosis are infrequently described and they are divided into tuberculoma and abscess.

In the present paper, we describe a case of cerebellar tuberculoma in aids patients with chiari malformation. Chiari malformations are a congenital heterogeneous group of disorders characterized by anatomic anomalies of the cerebellum, brain stem, and craniocervical junction associated with downward displacement of the cerebellum, alone or with lower medulla, into the cervical spine canal [1]. These disorders were first described by John Cleland in 1883 [2,3] and were classified later by Hans Chiari in 1891 into four groups [4].

\section{Case Report}

A 24-year-old woman infected with was admitted in January 2014 with a history of headaches, fever and productive cough in the previous six weeks. There was history of pulmonary tuberculosis in October 2013, with abandonment of antituberculous treatment at the third month. She had diagnosed HIV infection in august 2013.
The patient was a known case of Arnold-Chiari malformation, who presented with headache, and gait dysfunction lasting for several years, with deterioration in the weeks before admission, developing vertical nystagmus in the primary position, and became unable to walk unassisted.

On physical examination, the patient had important weight loss, moderate deshydratation, hepatosplenomegalia, ataxia and psychomotor slowness. The patient was admitted in hospital with the primary impression of cerebellar tonsil herniation. The neurological examination revealed upper motor neuron dysfunction with abnormal cerebellar function tests.

Altered laboratory tests were hemoglobin $11.2 \mathrm{~g} / \mathrm{dl}$, leucocytes 3000/ $\mathrm{mm}^{3}$, aspartate aminotransferase $54 \mathrm{UI} / \mathrm{l}$ and aminotransferase $53 \mathrm{UI} / \mathrm{l}$. A chest X-ray showed multiple micronodular lesions in both lungs compatible with military tuberculosis. The PPD and T. gondii were negative, The CD4+ lymphocytes count was 40 cells $/ \mathrm{mm}^{3}$ and the HIV viral load was 1790 copies $/ \mathrm{ml}$. The direct examination of sputum for AFB was positive.

Brain magnetic resonance imaging (MRI) confirmed a hypointensesignal mass in the left hemisphere of the cerebellum (Figure 1). Cervical spine MRI revealed a normal spinal column with herniation of the cerebellar tonsil.

Then the patient underwent microscopic craniotomy of posterior fossa (Figure 2). A cream-white tight mass was seen, and thus was totally resected. Surgical specimens of the cerebellar mass were submitted for histopathologic examination. Microscopic assessment confirmed a granulomatous inflammation composed of aggregation of epithelioid histiocytes associated with giant cells and lymphocyte cuffing foci of caseating necrosis compatible with tuberculoma. Treatment with isoniazid $400 \mathrm{mg}$, rifampicin $600 \mathrm{mg}$, pyrazinamid $2 \mathrm{~g}$, and ethambutol $1.2 \mathrm{~g}$ daily 


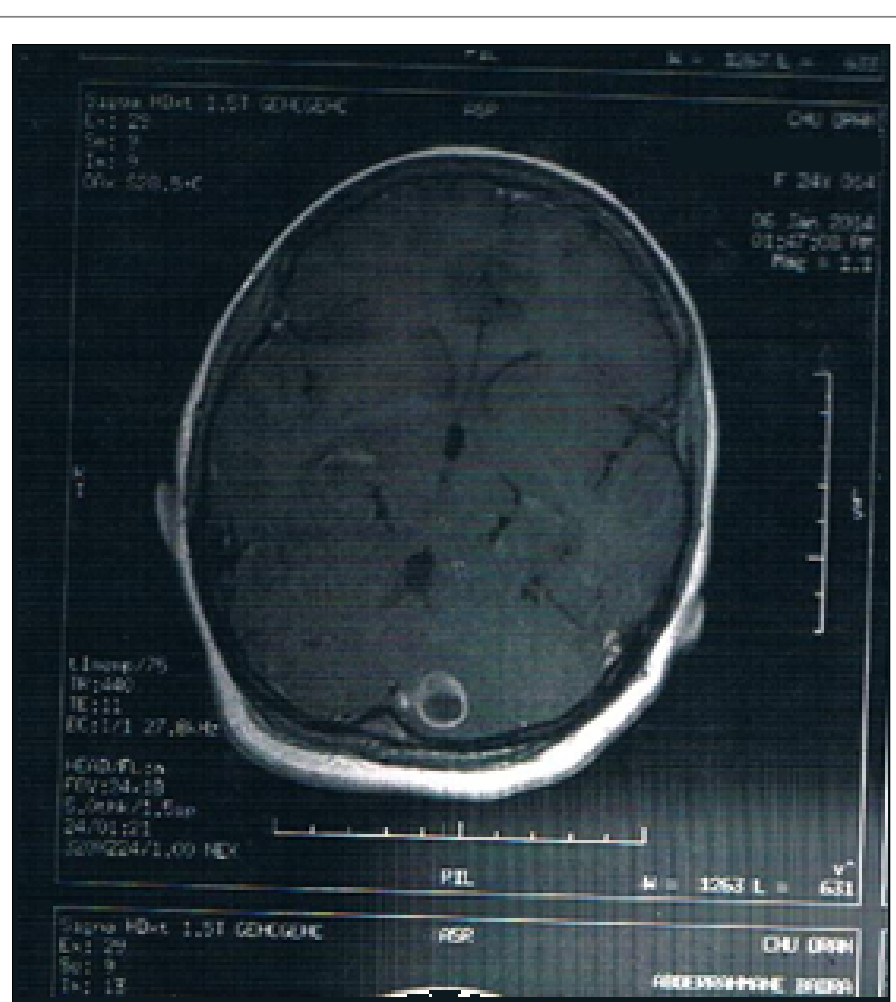

Figure 1: Brain magnetic resonance imaging. A hypointense signalmass in the left hemisphere of the cerebellum corresponding to asous-cortical postero-paramedian abscess measuring $13 \mathrm{~mm}$ showing unique ringenhancing lesion, surrounded by edema.

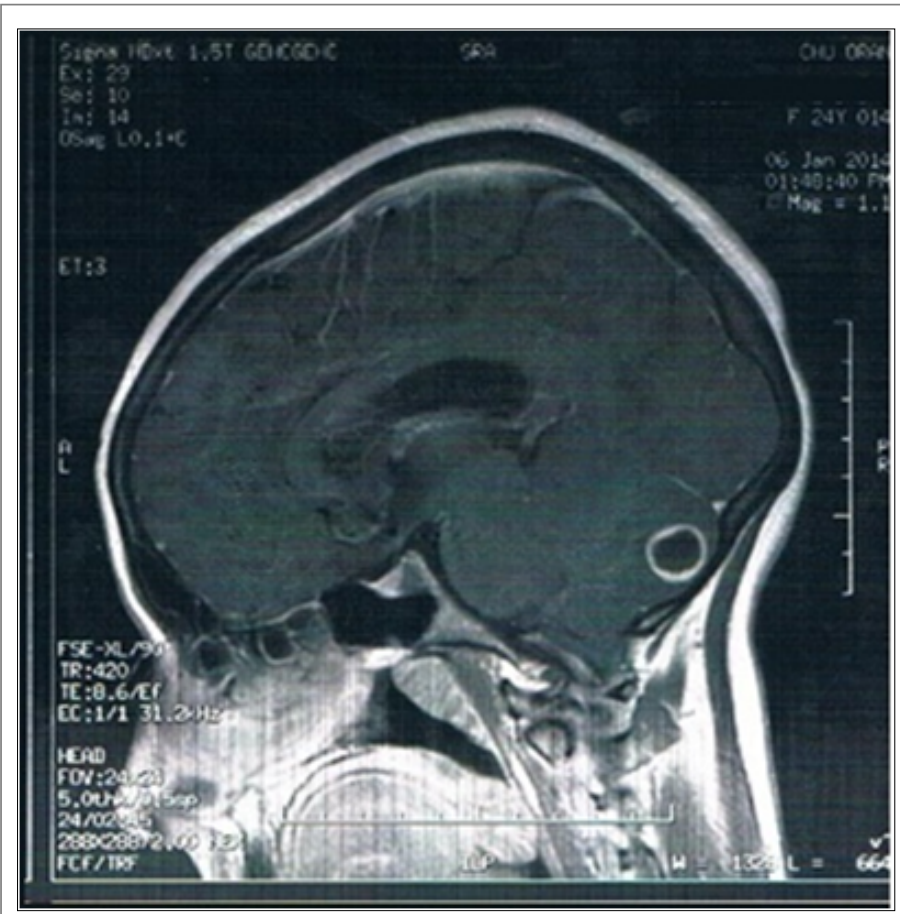

Figure 2: MRI of the head and spine (T2 weighted sagittal view) at time of presentation revealed a T1 hyposignal and hypersignal T2 lesion measuring $13 \mathrm{~mm}$ with annular enhancement corresponding to a souscortical postero-median abscess as well as an Arnold-Chiari type 1 malformation with effacement of the citern of posterior fossa and tonsillar herniation in the magnum over $05 \mathrm{~mm}$ descending to $\mathrm{C} 2$. was started. Four weeks later, the patient evidenced meaningful clinical and she was discharged to complete nine months of antituberculous treatment.

The patient has been followed until now. 18 months after surgery she has very mild residual cerebellar ataxia, eye movement disorder. She is able to eat a normal diet and walks independently.

\section{Discussion}

Chiari malformations are rare congenital anomalies with an estimated prevalence of 0.1 to $0.5 \%$ [5]. In most cases, due to the small posterior fossa, neural elements are crowded and impacted at the foramen magnum. Arnold-Chiari syndrome is usually detected prenatally or at birth.

Neuroimaging plays the main role in confirming the diagnosis, and MRI is the best imaging modality for evaluation [6]. MRI of the brain along with the entire spinal cord (cervical) is appropriate to demonstrate downward displacement of the inferior cerebellar vermis and medulla through the foramen magnum into the upper cervical canal. Despite these typical findings, brain MRI in our case showed an unusual mass in the left cerebellar hemisphere.

The patient underwent the most common procedure for ArnoldChiari malformations, which is posterior decompression via suboccipital craniotomy with duraplasty $[7,8]$. Simultaneously, posterior fossa craniotomy and resection of the mass were performed. Postoperative histopathologic evaluation showed that the mass was in fact a granulomatous tuberculoma.

The central nervous system tuberculosis found in $5-10 \%$ of patients with pulmonary tuberculosis [9]. These cases correspond to either latent infection reactivations or disseminated infections. The focal forms of CNS tuberculosis are infrequently described and they are divided into tuberculoma [10] and abscess. Moreover, there are tuberculomas which are solitary and large, multilocated and with an important mass effect. The cerebellar involvement is even less frequent. Up to now, only a few numbers of cases with cerebellar tuberculoma have been reported, and most of them are secondary to the pulmonary involvement $[11,12]$ and occurred in immunocompromised patients $[13,14]$.

On CT, intracranial tuberculoma may appear only as a nonspecific intracranial mass. Some authors $[15,16]$ have reported that, typically, a tuberculoma appears on CT as a solid or ring-like enhanced lesion, depending on its pathological stage.

A ring-enhanced area on CT scan or MRI is a characteristic appearance, but when there are no accompanied clinical manifestation or laboratory findings for tuberculosis, it would be so difficult to differentiate it from other CNS tumors. A hallmark of inflammation within the brain is an increase in water content at the affected site. High signal intensity on T2weighted images seems to denote inflammatory change. With application of new MR techniques such as proton spectroscopy and diffusion weighted imaging the MR specificity can be significantly increased [17-19].

Intracranial tuberculomas should be treated conservatively, since the majority of these lesions resolve completely with antituberculosis therapy.

On the other hand, surgery may be indicated if there is a rise in intracranial pressure, mass effect, or a lack of response to chemotherapy [20].

We conclude that a combination of surgery and chemotherapy is rational in cases of cerebellar tuberculoma associated with elevated intracranial pressure.

\section{Conclusion}

Despite being rare, CNS involvement of tuberculosis always should 
be kept in mind in any patient with neurological complaints from regions with a high endemic rate of tuberculosis, either in those being immunocompetent or immunologically incompetent. Surgical removal of intracranial tuberculomas can be justified in cases of raised intracranial pressure, whereas they are managed conservatively in all others cases.

\section{References}

1. Strayer A (2001) Chiari I malformation: clinical presentation and management. J Neurosci Nurs 33: 90-96, 104.

2. Carmel PW, Markesbery WR (1972) Early descriptions of the ArnoldChiari malformation. The contribution of John Cleland. J Neurosurg 37: 543-547.

3. Pearce JM (2000) Arnold Chiari, or "Cruveilhiercleland Chiari" malformation. J Neurol Neurosurg Psychiatry 68: 13.

4. Schijman E (2004) History, anatomic forms, and pathogenesis of Chiari I malformations. Childs Nerv Syst 20: 323-328.

5. Speer MC, Enterline DS, Mehltretter L (2003) Chiari type I malformation with or without syringomyelia: Prevalence and genetics. J Genet Couns 12: 297-311.

6. Guillen A, Costa JM (2004) Spontaneous resolution of a Chiari I malformation associated syringomyelia in one child. Acta Neurochir (Wien) 146: 187-191

7. Seijo-Martínez M, Diz-Aren J, Castro-del Río M, Viladrich A, GonzálezCarreró J (2000) Paradoxical appearance of tuberculoma and formation of a cerebellar abscess in a patient with human immunodeficiency virus treated with triple antiretroviral therapy. Rev Neurol 31: 697-698.

8. Tubbs RS, McGirt MJ, Oakes WJ (2003) Surgical experience in 130 pediatric patients with Chiari I malformations. J Neurosurg 99: 291-296.

9. Bayindir C, Mete O, Bilgic B (2006) Retrospective study of 23 pathologically proven cases of central nervous system tuberculomas. Clin Neurol Neurosurg 108: 353-357.
10. Navarrete AC, Rosas KM, Sáez MD, Tenhamm FE, Nogales-Gaete $J$ (2008) Cerebellous syndrome by infratentorial tuberculomas and multisystemic tuberculosis in AIDS patient. Rev Chilena Infectol 25: 122-126.

11. Tanioka D, Abe T, Ikeda $H$, Kushima M (2005) A case of cerebellar tuberculoma. No Shinkei Geka 33: 919-923.

12. Kochanek M, Hartmann P, Dölken G, Salzberger B, Diehl V, et al. (1998) Intracerebellar tuberculoma in a patient with AIDS. A case report. Zentralbl Bakteriol 287: 427-432.

13. Naama O, Boulahroud O, Elouennass M, Akhaddar A, Gazzaz M, et al. (2010) Primary tuberculous cerebellar abscess in an immunocompetent adult. Intern Med 49: 875-876.

14. Oshinowo AG, Blount BW, Golusinski LL (1998) Tuberculous cerebellar abscess. J Am Board Fam Pract 11: 459-464.

15. Arseni $C$ (1958) Two hundred and one cases of intracranial tuberculoma treated surgically. J Neurol Neurosurg Psychiatry 21: 308-311.

16. Bhargava S, Tandon PN (1980) Intracranial tuberculomas. A CT study. Br J Radiol 53: 935-945.

17. Kaminigo M, Ishihasu H, Morikawa M, Suzuki Y, Shibata S (2002) Proton MR spectroscopy and diffusion weighted MR imaging for the diagnosis of intracranial tuberculomas. Report of two cases. Neurol Res 24: 537-543.

18. Gupta RK, Kathuria MK, Pradhan S (1999) Magnetization transfer MR imaging in CNS tuberculosis. AJNR Am J Neuroradiol 20: 867-875.

19. Nabiuni M, Sarvarian S (2011) Primary cerebellar tuberculoma in Arnold-chiari malformation mimicking posterior cranial fossa tumor: the first report. Global Spine J 1: 19-22.

20. Dechambenoit G, Boni NG, Santini JJ, Ba Zeze V, Beaumel A, et al. (1993) Tuberculous abscess of the cerbellum. Neurochirurgie 39: 326329 